PREPARED FOR THE U.S. DEPARTMENT OF ENERGY, UNDER CONTRACT DE-AC02-76CH03073

PPPL-3571

PPPL-3571

UC-70

Turbulence Scattering of High Harmonic Fast Waves

M. Ono, J. Hosea, B. LeBlanc, J. Menard, C.K. Phillips, R. Wilson,

P. Ryan, D. Swain, J. Wilgen, S. Kubota, and T.K. Mau

May 2001

NM|

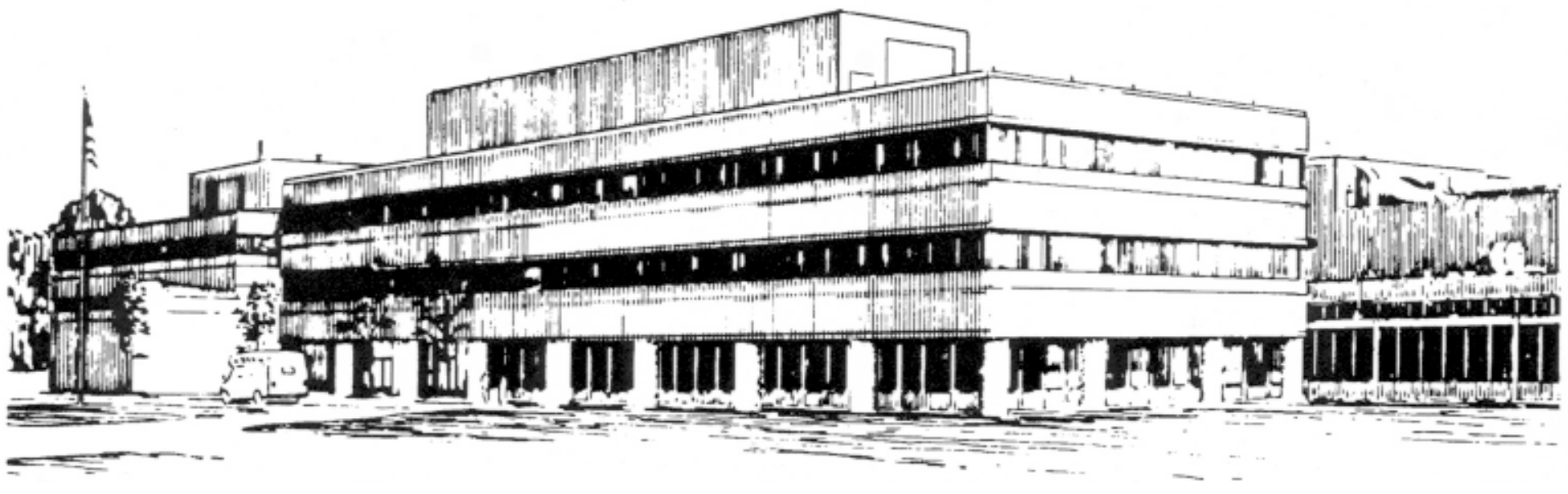

PRINCETON PLASMA PHYSICS LABORATORY PRINCETON UNIVERSITY, PRINCETON, NEW JERSEY 


\section{PPPL Reports Disclaimer}

This report was prepared as an account of work sponsored by an agency of the United States Government. Neither the United States Government nor any agency thereof, nor any of their employees, makes any warranty, express or implied, or assumes any legal liability or responsibility for the accuracy, completeness, or usefulness of any information, apparatus, product, or process disclosed, or represents that its use would not infringe privately owned rights. Reference herein to any specific commercial product, process, or service by trade name, trademark, manufacturer, or otherwise, does not necessarily constitute or imply its endorsement, recommendation, or favoring by the United States Government or any agency thereof. The views and opinions of authors expressed herein do not necessarily state or reflect those of the United States Government or any agency thereof.

\section{Availability}

This report is posted on the U.S. Department of Energy's Princeton Plasma Physics Laboratory Publications and Reports web site in Calendar Year 2001. The home page for PPPL Reports and Publications is: http://www.pppl.gov/pub_report/

DOE and DOE Contractors can obtain copies of this report from:

U.S. Department of Energy

Office of Scientific and Technical Information

DOE Technical Information Services (DTIS)

P.O. Box 62

Oak Ridge, TN 37831

Telephone: (865) 576-8401

Fax: (865) 576-5728

Email: reports@adonis.osti.gov

This report is available to the general public from:

National Technical Information Service

U.S. Department of Commerce

5285 Port Royal Road

Springfield, VA 22161

Telephone: 1-800-553-6847 or

(703) 605-6000

Fax: (703) 321-8547

Internet: http://www.ntis.gov/ordering.htm 


\title{
Turbulence Scattering of High Harmonic Fast Waves*
}

\author{
M. Ono, J. Hosea, B. LeBlanc, J. Menard, C.K. Phillips, R. Wilson, Princeton \\ Plasma Physics Laboratory, P. Ryan, D. Swain, J. Wilgen, ORNL, \\ S. Kubota, UCLA, T. K. Mau, UCSD,
}

\begin{abstract}
Effect of scattering of high harmonic fast magnetosonic waves (HHFW) by low frequency plasma turbulence is investigated. Due to the similarity of the wavelength of HHFW to that of the expected low frequency turbulence in the plasma edge region, the scattering of HHFW can become significant under some conditions. The scattering probability increases with the launched wave parallel-phase-velocity as the location of the wave cut-off layer shifts toward lower density edge. The scattering probability can be reduced significantly with higher edge plasma temperature, steeper edge density gradient, and magnetic field. The theoretical model could explain some of the HHFW heating observations on NSTX.
\end{abstract}

\section{INTRODUCTION}

Multi-megawatt level high harmonic fast wave ${ }^{1}$ (HHFW) experiments are currently being conducted on the National Spheical Torus Experiment (NSTX). ${ }^{2,3}$ With application of HHFW, the central electron temperatures was successfully heated to $\approx 1.2 \mathrm{keV}$, nearly tripling the initial ohmic temperature. While the experimental undertaking has just begun, the observed HHFW heating efficiency thus far appears to vary significantly with the antenna phasing and the plasma conditions including working gases. The slowest phase $\left(k_{\|}=14 \mathrm{~m}^{-1}\right)$ thus far appears to be more efficient for heating ohmic plasmas as compared to the faster phasing $\left(k_{\|}=7 \mathrm{~m}^{-1}\right)$. However, linear calculations predict good core power depositions for both phases. In addition, HHFW applied on helium plasmas generally show better heating efficiency compared to deuterium plasmas though the wave propagation characteristics should be nearly identical for helium and deuterium plasmas. In short, the linear theory alone has not thus far fully explained the experimental observations. In this paper, we examine a possible role of wave-wave scattering of launched HHFW by low frequency plasma turbulences in the plasma edge region. As the launched HHFW propagates into plasma interior, it goes through a region where the wavelength is comparable to the local turbulence wavelength at the plasma edge region where the turbulence amplitude is generally high. (See Fig. 1) This condition tends to enhance the wave-wave mode-coupling interactions and, thus, increases the probability of scattering for HHFW. If the launched HHFW suffers excessive scattering near the plasma edge region, the wave power propagation and deposition can be altered significantly from the linear theory predictions. The present paper is an initial theoretical and experimental assessment to see if the scattering can be playing a significant role for HHFW and to identify means to minimize the scattering probability if it turns out to be excessive.

MODEL OF HHFW LOW FREQUENCY TURBULENCE SCATTERING

In investigating the problem of low frequency turbulence scattering of HHFW, we shall use the experimentally motivated Gaussian spectrum, i.e., $S(\xi)=\left[\pi \xi_{0}^{2}\right]^{-1}\left|\hat{n}_{e}\right|^{2} \exp \left(-\xi^{2} / \xi_{0}^{2}\right)$ for the low frequency turbulence spectra, where $\left|\hat{n}_{e}\right|$ is the normalized density fluctuation amplitude typically observed to be a few $\%$ in the plasma edge region. The mean drift turbulence wave number 
$\xi_{0}$ is considered to be order of ion-Larmor-radius typically $\xi_{0} \rho_{\mathrm{i}}=\mathrm{C}_{\mathrm{D}} \approx 0.1-$ 1.0 where the drift turbulence growth rate is maximum. ${ }^{4}$ Due to the turbulence nature of the low frequency fluctuations, we also assume that the scattering can be described by the weak turbulence approximation in a wave-wave coupling equations. ${ }^{5}$ Assuming slow time evolution compared to the wave oscillation time scale, one can the obtain the mode-coupling (scattering) equation.6,7 It should be noted that in this high harmonic frequency regime, the ExB term is significantly larger (by $\omega / \Omega_{i} \cong 20$ ) than the ion polarization drift term. The main scattering effect here is the perpendicular wave number vector rotation along the local magnetic axis. The scattering probability $P_{S}$ is defined as an integral of inverse scattering length as a launched wave propagates from radial position $r_{1}$ and $r_{2}$. We shall now investigate the HHFW wave scattering dependence on various edge plasma parameters.

\section{PARAMETRIC DEPENDANCE OF SCATTERING LENGTH}

Given the density turbulence fluctuation spectrum, the question is how the scattering length depends on the wave and plasma parameters. The main variables which affect the scattering length are the wave frequency $f$, the parallel wave number $k_{\|}$, plasma density $n_{e}$, magnetic field $B$, normalized low frequency fluctuation amplitude $\left|\hat{n}_{e}\right|$, drift turbulence wave number $\xi_{0}$, and the spectrum coefficient $C_{D}$. The dependence on the normalized fluctuation amplitude itself is trivial (i.e., $L_{S} \propto\left|\hat{n}_{e}\right|^{2}$ ). For this reason, we use 5\% for $\left|\hat{n}_{e}\right|$ throughout this paper since one can readily scale the fluctuations level dependence.

A. Density and Launched $\boldsymbol{n}_{\Perp}$ Dependence - As shown in Fig. 1, the HHFW wave length undergoes a large change as the wave propagates from the plasma edge into the plasma core; $k_{\perp}<<\xi_{0}$ near the antenna to $k_{\perp}>>\xi_{0}$ in the plasma core. The wave therefore propagates through a region of $k_{\perp} \approx \xi_{0}$ where the interaction with the drift turbulence is enhanced. To illustrate this effect, in Fig. 2 , we plot the scattering length $L_{S}$ as a function of plasma density for the three representative $k_{\|}$as labeled. As can be seen by comparing Figs 1 and 2, the $90^{\circ}$ scattering length assumes a minimum near the $k_{\perp} \approx \xi_{0}$. Somewhat surprisingly, the lower $k_{\|}$waves suffer considerably more scattering for otherwise identical wave and plasma parameters. The main reason is the cut-off density. For $k_{\|}=$ $3.5 \mathrm{~m}^{-1}$, the wave starts to propagate at much lower density, $\mathrm{n}_{\mathrm{e}} \approx 7 \times 10^{10} \mathrm{~cm}^{-3}$ where as for $k_{\|}=14 \mathrm{~m}^{-1}$, the corresponding density is $1.1 \times 10^{12} \mathrm{~cm}^{-3}$. Also larger $k_{\|}$reduces the $k_{\perp}$ value, which tends to reduce the scattering as well. The scattering probability for the case $k_{\|}=7 \mathrm{~m}^{-1}$ can be significant $\approx 50 \%$ for a density ramp distance of $10 \mathrm{~cm}$. A narrower propagation region (or a steeper density edge gradient) results in a smaller scattering probability. The scattering situation gets even more challenging for the fastest phasing case $k_{\|}=3.5 \mathrm{~m}^{-1}$. An obvious remedy is to steepen the edge density so that the radial extent of the low density region $\left(n_{\mathrm{e}} \leq 1 \times 10^{13} \mathrm{~cm}^{-3}\right)$ can be minimized since most of the scattering takes place in the low density plasma. 
B. Plasma Temperature and Other Parametric Dependence- Since the HHFW wave behavior at the plasma edge can be described through cold plasma wave theory, the plasma temperature dependence for the scattering problem only enters indirectly through the spectrum of the low frequency turbulence since the mean drift turbulence wave number $\xi_{0}$ is considered to be order of ion-Larmorradius. Interestingly the higher temperature generally reduces the scattering probability for HHFW due to shifting of the $k_{\perp} \approx \xi_{0}$ point to lower density thus reducing the over all scattering probability. The same result can be obtained with corresponding reduction in $C_{D}$. Another possible knob is the magnetic field. An increase in the magnetic field value $B$ increases the phase and group velocity $\left(\approx \mathrm{V}_{\text {Alfven }} \propto \mathrm{B}\right)$ of the wave thus reducing the scattering probability.

\section{EXPERIMENTAL OBSERVATION}

This launched wave spectrum dependence of fluctuation scattering can explain the observed higher heating efficiency for the slower phased wave $\left(k_{\|}=\right.$ $\left.14 \mathrm{~m}^{-1}\right)$ compared to the faster phase case $\left(k_{\|}=7 \mathrm{~m}^{-1}\right)$. The observed higher heating efficiency for the helium plasma compared to the hydrogen plasma is more subtle since the wave physics should be identical for helium and deuterium plasmas. The microwave reflectometry measurements of edge turbulences show relatively similar fluctuation levels per given density for both plasmas. ${ }^{8}$ Only significant difference observed thus far is the edge most channel of the Thomson scattering density values. The measured edge density $(R=153 \mathrm{~cm})$ is indeed significantly higher for helium than for deuterium. For example, the measured edge density for a helium discharge (shot \#104487) at the plasma edge during HHFW heating $(\mathrm{t}=0.197 \mathrm{sec})$ is $7 \times 10^{12} \mathrm{~cm}^{-3}$ whereas for a similar deuterium discharge (shot \#104474), the measured density is only $2.5 \times 10^{12} \mathrm{~cm}^{-3}$. The higher edge density reduces the low density edge width between the antenna and the main plasma thus reducing the scattering probability. The higher edge density plasmas generally show higher heating efficiency even among the deuterium plasmas. ${ }^{2}$ The heating efficiency vs. plasma gap scan also support this trend. One should note that the antenna loading (thus the ability to launch the rf power) is not sensitive to the edge plasma parameters. 9 The sensitivity of wave power deposition with the turbulence scattering can be explored by using ray tracing calculations. ${ }^{10}$ An initial ray tracing calculation appears to show that even a modest level of scattering can profoundly affect the wave power deposition profiles.

\section{CONCLUSIONS AND DISCUSSIONS}

It is shown that the high harmonic fast wave (HHFW) can be scattered from low frequency turbulence as it propagates from the plasma edge to the core. As illustrated in this analysis, the higher $k_{\|}$HHFW is much less prone to the scattering thus can have a better heating efficiency, which is consistent with the experimental observation. Higher edge density (or narrower edge region) can also reduce scattering. This could expalin better heating efficiency observed in helium plasmas (as compared to deuterium plasmas) as the edge Thomson scattering density is significantly higher for helium than for deuterium. The heating efficiency also appears to correlated with the edge density even for deuterium plasmas. To improve heating efficiency further, one could envision some edge density enhancement schemes such as the methane injection shown 
to be effective on JET lower hybride wave experiment. ${ }^{11}$ The analyses also show that higher edge temperature, lower turbulence wave number, and higher magnetic field can reduce scattering. The H-mode edge with high edge density and temperature pedestal may be advantageous for minimizing the turbulence scattering. Since the faster phase will be used for the strongly heated high $\mathrm{T}_{\mathrm{i}} /$ high $\beta$ region, this overall trend is favorable.

*This work was supported by US. D.o.E. Contract DE-AC02-76-CHO-3073.

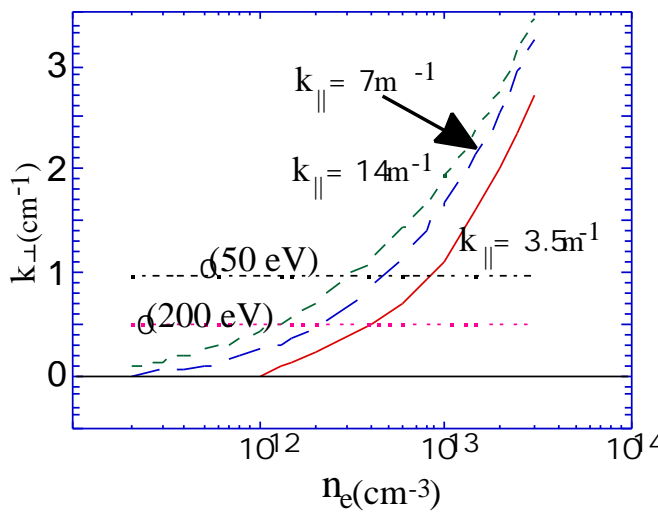

Fig. 1. HHFW perpendicular wave number as a function of $n_{e}$ for various $k_{\|}$ as labeled. $B=2.0 \mathrm{kG}, f=30 \mathrm{MHz}$, and deuterium (helium) plasma.

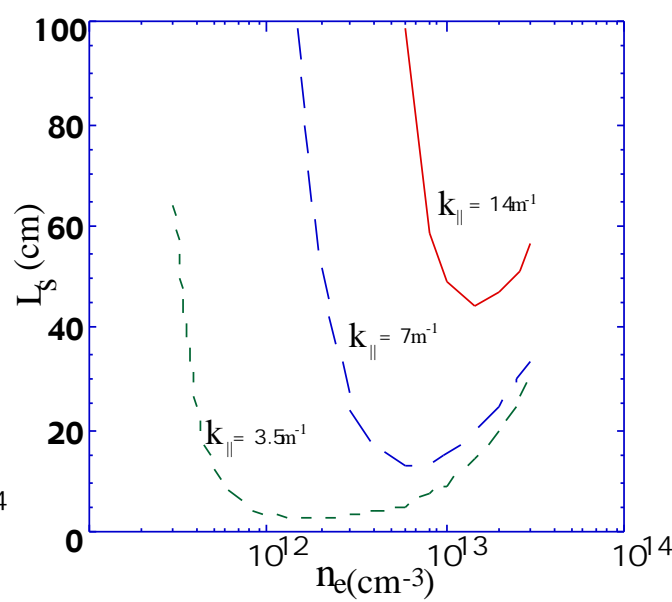

Fig. 2. Low frequency scattering length $L_{S}$ as a function of $n_{e}$. for various $k_{\|}$as labeled. $B=2.0 \mathrm{kG}, \mathrm{T}_{\mathrm{i}}=50 \mathrm{eV}, \mathrm{C}_{\mathrm{D}}=$ $0.5,=0.05$, and $f=30 \mathrm{MHz}$, and deuterium plasma.

\section{REFERENCES}

${ }^{1}$ M. Ono, Physics of Plasmas 2, 4075 (1995).

2 J. R. Wilson et al., Plasma Phys. Contr. Nuclear Fusion Research (IAEA, 2000).

3 B. LeBlanc et al., this conference.

4 See for example, G. Rewoldt, et al., Phys. Plasmas 3. 1 (1996). T.S. Hahm et al., Phys. Plasmas 6, 922 (1999).

5 R.Z. Sagdeev and A. A. Galeev, Nonlinear Plasma Theory (Benjamin, Reading, Massachusetts, 1969, p.20. B. Coppi and M. N. Rosenbluth, Ann. Phys. (N.Y.) 55, 207 (1969).

6 E. Ott, Phys. Fluids 22, 1732 (1979).

7 M. Ono, Phys. Fluids 25, 990 (1982).

8 S. Kubota et al., Review of Scientific Instrument 72, 348 (2001).

9 D. W. Swain et al., this conference.

10 T.K. Mau, S.C. Chiu, R.W. Harvey, EPS Conf. Abstracts on Radiofrequency Heating and Current Drive of Fusion Devices, Vol. 16E, Brussels (1992) 181.

11 A Tuccillo et al., this conference. 


\section{External Distribution}

Plasma Research Laboratory, Australian National University, Australia

Professor I.R. J ones, Flinders University, Australia

Professor J oão Canalle, Instituto de Fisica DEQ/IF - UERJ , Brazil

Mr. Gerson O. Ludwig, Instituto Nacional de Pesquisas, Brazil

Dr. P.H. Sakanaka, Instituto Fisica, Brazil

The Librarian, Culham Laboratory, England

Library, R61, Rutherford Appleton Laboratory, England

Mrs. S.A. Hutchinson, JET Library, England

Professor M.N. Bussac, Ecole Polytechnique, France

Librarian, Max-Planck-Institut für Plasmaphysik, Germany

J olan Moldvai, Reports Library, MTA KFKI-ATKI, Hungary

Dr. P. Kaw, Institute for Plasma Research, India

Ms. P.J . Pathak, Librarian, Insitute for Plasma Research, India

Ms. Clelia De Palo, Associazione EURATOM-ENEA, I taly

Dr. G. Grosso, Instituto di Fisica del Plasma, Italy

Librarian, Naka Fusion Research Establishment, J AERI, J apan

Library, Plasma Physics Laboratory, Kyoto University, J apan

Research Information Center, National Institute for Fusion Science, J apan

Dr. O. Mitarai, Kyushu Tokai University, J apan

Library, Academia Sinica, Institute of Plasma Physics, People's Republic of China

Shih-Tung Tsai, Institute of Physics, Chinese Academy of Sciences, People's Republic of China

Dr. S. Mirnov, TRINITI, Troitsk, Russian Federation, Russia

Dr. V.S. Strelkov, Kurchatov Institute, Russian Federation, Russia

Professor Peter Lukac, Katedra Fyziky Plazmy MFF UK, Mlynska dolina F-2, Komenskeho Univerzita, SK-842 15 Bratislava, Slovakia

Dr. G.S. Lee, Korea Basic Science Institute, South Korea

Mr. Dennis Bruggink, Fusion Library, University of Wisconsin, USA

Institute for Plasma Research, University of Maryland, USA

Librarian, Fusion Energy Division, Oak Ridge National Laboratory, USA

Librarian, Institute of Fusion Studies, University of Texas, USA

Librarian, Magnetic Fusion Program, Lawrence Livermore National Laboratory, USA

Library, General Atomics, USA

Plasma Physics Group, Fusion Energy Research Program, University of California at San Diego, USA

Plasma Physics Library, Columbia University, USA

Alkesh Punjabi, Center for Fusion Research and Training, Hampton University, USA

Dr. W.M. Stacey, Fusion Research Center, Georgia Institute of Technology, USA

Dr. J ohn Willis, U.S. Department of Energy, Office of Fusion Energy Sciences, USA

Mr. Paul H. Wright, Indianapolis, Indiana, USA 
The Princeton Plasma Physics Laboratory is operated by Princeton University under contract with the U.S. Department of Energy.

\author{
Information Services \\ Princeton Plasma Physics Laboratory \\ P.O. Box 451 \\ Princeton, NJ 08543
}

Phone: 609-243-2750

Fax: 609-243-2751

e-mail: pppl_info@pppl.gov

Internet Address: http://www.pppl.gov 